DOI: $10.14451 / 2.124 .53$

\title{
ПОДХОД К ОБЕСПЕЧЕНИЮ УСТОЙЧИВОГО РАЗВИТИЯ РЕАЛЬНОГО СЕКТОРА ЭКОНОМИКИ РОССИИ
}

\section{(c) 2018 Гудкова Елизавета Евгеньевна}

старший преподаватель кафедры экономики в энергетике и промышленности Национальный исследовательский университет «Московский Энергетический Институт» 111250, г. Москва, ул. Красноказарменная, д. 14

E-mail: gudliza@mail.ru

\section{(c) 2018 Курочкин Дмитрий Сергеевич}

кандидат экономических наук, доцент кафедры электроснабжения промышленных предприятий Национальный исследовательский университет «Московский Энергетический Институт»

\section{0, г. Москва, ул. Красноказарменная, д. 14}

E-mail: dskurochkin@mail.ru,

\section{(c) 2018 Рогалев Николай Дмитриевич}

доктор технических наук, профессор, заведующий кафедрой тепловых электрических станций ректор

Национальный исследовательский университет «Московский Энергетический Институт»

111250 , г. Москва, ул. Красноказарменная, д. 14

E-mail: rogalevnd@mpei.ru

Динамика прироста новых знаний определяет прогноз устойчивого развития национальной экономики. Показана роль национальных исследовательских университетов как генератора системного знания для формирования условий реализации устойчивого развития российских предприятий.

Ключевые слова: устойчивое развитие; технологический уклад; бизнес-уклад; патент; ВВП; национальный исследовательский университет; система менеджента; техническая политика.

Ввиду геополитических процессов снижается уровень вовлеченности России в международные процессы трансфера высоких технологий. Двусторонние санкции, препятствующие интеграции РФ в глобальное экономическое пространство, несут риск непреодолимого в будущем технологического отставания от стран-лидеров научно-технического развития. Ввиду усугубления разрыва в эффективности отечественных и зарубежных наукоемких отраслей, велика вероятность эскалации деиндустриализации. Потеря контроля над производством наукоемких высокотехнологичных систем, необходимых для реализации стратегически важных видов деятельности, таких как энергетика, приведет к необходимости их экспорта на крайне невыгодных условиях, что в конечном итоге приведет к ослаблению и потере суверенитета России.

При этом можно констатировать, что ползучая изоляция РФ лишь подчеркнула негативную тенденцию утраты позиций в международной технологической гонке. Статистика международных патентных заявок [1] (табл. 1, рис. 1) наглядно демонстрирует положение России в области технологического лидерства.

Эксперты Всемирной Организации Интеллектуальной Собственности (WIPO) [2] отмечают, что при сохранении трендов Китай уже опередил Японию по числу поданных заявок и в те-

Таблица 1. Статистика международных патентных заявок за 2007-2017

\begin{tabular}{|c|c|c|c|c|c|c|c|c|c|c|c|}
\hline Страна/год & $\mathbf{2 0 0 7}$ & $\mathbf{2 0 0 8}$ & $\mathbf{2 0 0 9}$ & $\mathbf{2 0 1 0}$ & $\mathbf{2 0 1 1}$ & $\mathbf{2 0 1 2}$ & $\mathbf{2 0 1 3}$ & $\mathbf{2 0 1 4}$ & $\mathbf{2 0 1 5}$ & $\mathbf{2 0 1 6}$ & $\mathbf{2 0 1 7}$ \\
\hline США & 54042 & 51642 & 45627 & 45029 & 49060 & 51207 & 57239 & 61477 & 57385 & 56594 & 56624 \\
\hline Германия & 17821 & 18855 & 16797 & 17568 & 18851 & 18855 & 17927 & 17983 & 18072 & 18307 & 18982 \\
\hline Япония & 27743 & 28760 & 29802 & 32150 & 38874 & 43660 & 43918 & 42381 & 44235 & 45209 & 48208 \\
\hline Китай & 5455 & 6120 & 7900 & 12296 & 16402 & 18627 & 21516 & 25548 & 29846 & 43091 & 48882 \\
\hline Россия & 689 & 763 & 711 & 798 & 809 & 843 & 875 & 948 & 792 & 894 & 1097 \\
\hline
\end{tabular}




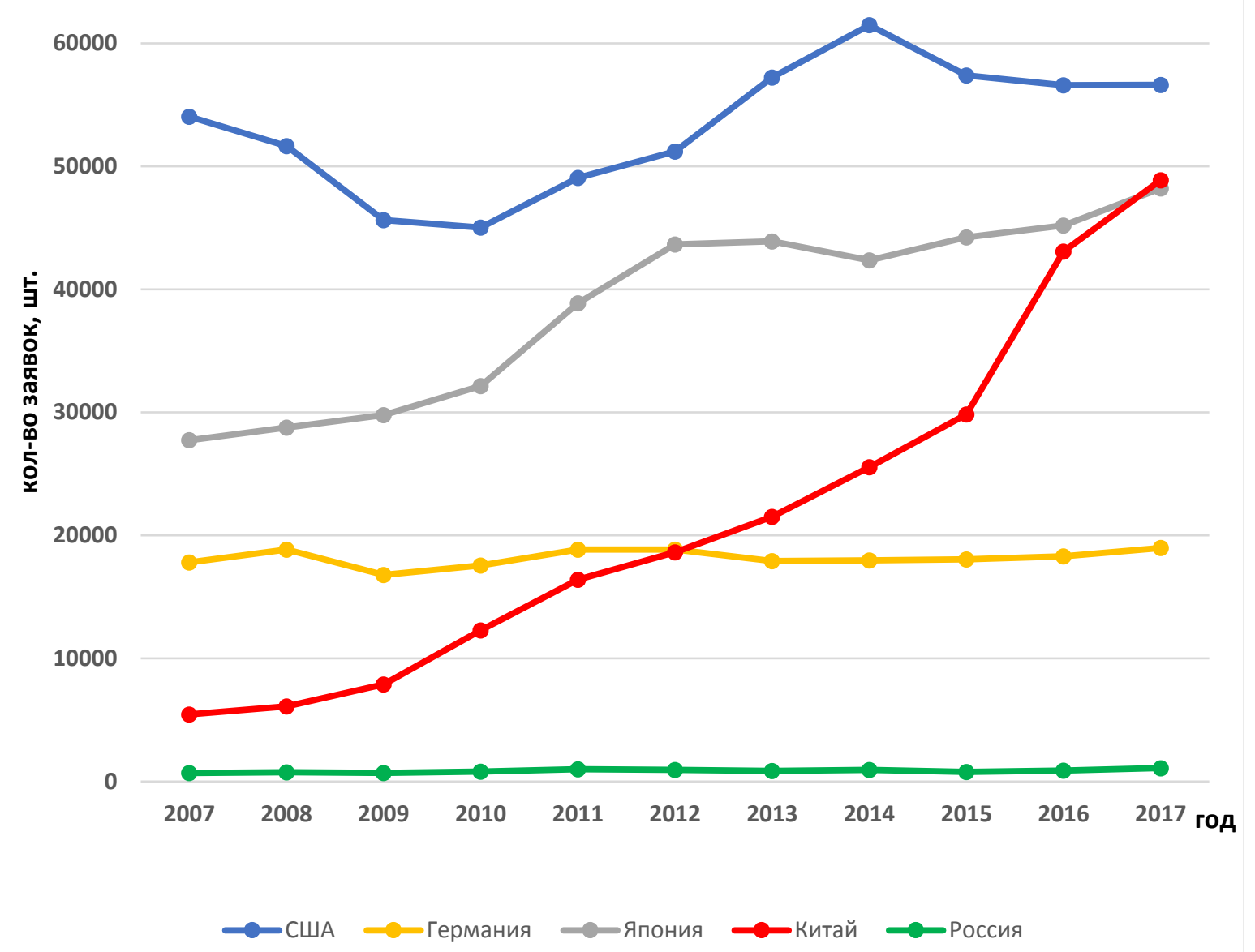

Puc. 1. Динамика международных патентных заявок за 10 лет

чение трех лет вырвется в лидеры международного патентования. При этом всего 30 лет назад Россия существенно опережала Китай по уровню изобретений [3]. Получается, что Китаю удалось создать благоприятную среду для интеграции нововведений в экономику, в то время как РФ практически не развивала на государственном уровне механизмы разработки и внедрения новых знаний в промышленность.

Известную корреляцию годового валового внутреннего продукта и уровня реализованных патентов можно использовать для прогноза динамики ВВП, т.к. росту ВВП в последующем году способствует реализация патентов в предыдущих годах [3]. Согласно рис.1 такой прогноз для России носит неблагоприятный характер. Очевидна необходимость стимулирования изобретательской деятельности и выстраивания механизмов интеграции ее результатов в экономику РФ для обеспечения ее устойчивого развития.

К анализу причин положительной динамики международных патентных заявок Китая и стагнации России можно подойти с позиции теории технологических (бизнес) укладов. Со- поставив уровень технологического уклада (ТУ) России (СССР) и Китая в 1990-м и 2010-м годах [4] можно увидеть, что Китай переместился с третьего уровня ТУ на пятый, в тот же период Россия медленно развивалась в рамках 4-го ТУ.

В силу ряда причин в РФ наблюдается низкий процент инновационных предприятий. Совокупный уровень инновационной активности организаций России составляет 8,4\%, Китая - 41,3\% (лидер по данному показателю: Швейцария $-75,3 \%$ ) [5]. Очевидно, что в России на данный момент отсутствуют устойчивые механизмы инновационного развития, несмотря на провозглашение разного рода государственных деятелей о необходимости модернизации и построении инновационной экономики. При этом в РФ есть организаторы - флагманы инноваций, которые могут стать источником лучших практик для всех участников социально-экономической деятельности.

Согласно международному стандарту ИСО 9001:2015 одним из основных принципов качественного управления является стремление к постоянному улучшению. Очевидно, что улуч- 
шение лишь в контексте внедрения высоких технологий в производство не может обеспечить устойчивого социально-экономического роста. Большое количество наработок советских ученых и изобретателей не смогли повлиять на динамику ВВП постсоветской России. В своих работах $[6,7,8]$ профессор Национального исследовательского университета «МЭИ» В.К. Лозенко доказал в контексте доминирования того или иного уклада ключевую роль факторов, выпадающих из фокуса внимания при анализе экономики с позиции используемых технологий: инфраструктура, система менеджмента и человеческие ресурсы. «Перечисленные ресурсы взаимосвязаны и взаимообусловлены. Ни в стране, ни в регионе, ни в отрасли и ни в организации не может быть внедрена никакая новая прорывная технология, если не будут произведены соответствующие изменения в системе менеджмента, а персонал не обретет необходимые компетенции работы с новой технологией.» [7].

Анализируя технические политики современных российских энергокомпаний в разрезе управления инновациями можно встретить определения инновационной деятельности, критерии отнесения к оной, заявления о ее необходимости, иногда даже перечня инновационных текущих и будущих проектов. Но описание действующих организационных механизмов разработки, импорта, трансляции и распространения новых знаний в таких документах обычно отсутствует. То есть потребность качественного управления изменениями осознается, провозглашается, но не реализуется в полной мере. Приводя во внимание выводы [6] можно утверждать, что причиной такого положения является отсутствие должного количества квалифицированных кадров, компетентных в вопросах управления изменениями. Можно сказать еще острее - в низком уровне культуры управления организацией в контексте необходимости ее постоянного улучшения, обозначенной в МС ИСО серии 9000.

Одной из ключевых характеристик того или иного бизнес-уклада является энергоэффективность основных производственных процессов [8]. Обеспечение устойчивого развития организаций, отраслей, экономики в целом невозможно без повышения энергоэффективности. Для управления энергоэффективностью требуется организационно-экономический механизм, который необходимо проектировать и внедрять индивидуально в контексте каждого отдельного предприятия. Ведь для каждой организации необходима разработка системы индикаторов энергоэффективности, настроенная на обеспечение ее устойчивого развития.

Очевидной становится роль национальных исследовательских университетов в построении организационных механизмов формирования условий для устойчивого развития реального сектора экономики. Ведь именно в многопрофильных университетах возможна результативная генерация системного знания в области управления интегрированными междисциплинарными процессами. При этом НИУ, благодаря своей образовательной функции, могут поставлять на рынок труда отраслевых специалистов в области управления, изначально компетентных в планировании производства, синхронизированного с поставщиками и потребителями. Основная задача менеджмента - согласование целей всех групп, заинтересованных в деятельности организации. Поэтому наличие компетентных управленцев является базовым условием обеспечения устойчивого развития экономики. Благоприятная для роста среда может существовать только в результате целевого взаимодействия государства - регулятора и гаранта отношений, научно-образовательного комплекса - исполнителя НИР и поставщика квалифицированных кадров, частного бизнеса и госкорпораций - поставщиков лучших управленческих практик и производителей инфраструктур, товаров и услуг для улучшения уровня жизни граждан страны. Именно в зоне пересечения интересов происходит наиболее результативное использование ресурсов участников устойчивого развития. Возникающий синергетический эффект приводит не только к появлению новых «прорывных» технологий и управленческих практик, но и к их повсеместному распространению и внедрению. Данный эффект показан в рамках модели всестороннего партнерства «тройная спираль» [9].

В рамках трансляции лучших управленческих практик существует объективная задача восстановления устойчивых связей реального сектора экономики и научно-образовательной системы России, утраченных в результате переориентации экономики с затратной на рыночную. Данная задача может быть решена за счет построения механизма взаимодействия, основанного на согласовании целей государства, вуза 
и предприятий, предполагающего вовлечение контрагентов во все аспекты сотрудничества. Такой механизм взаимодействия организаций реального сектора экономики с вузом [10] предполагает два сценария построения отношений. С одной стороны, компании на прогрессивном уровне бизнес-уклада, заинтересованные в компетентных работниках, участвуют в формировании вузовских программ обучения, задают тематики диссертаций, НИР и ОКР, их представители транслируют свой опыт в рамках открытых лекций, консультаций и организации практик студентов. С другой стороны компании на более низком уровне бизнес-уклада становятся заказчиками проектов построения интегрированных систем менеджмента, позволяющих результативно управлять внедрением новых технологий и организационных принципов управления энергоэффективностью. Исполнителем подобных проектов, а также поставщиком персонала и знаний становится НИУ, который за счет такого взаимодействия повышает процент трудоустройства своих выпускников по профилю полученного образования. При этом к собственной системе управления вузом должны применяться требования соответствия и даже превосходства уровня систем менеджмента доминирующего бизнес-уклада. Необходимо гло- бально (на макроуровне) и локально (на микроуровне) решать задачу согласования структурных и параметрических (экологических, экономических, социальных, энергетических, информационных, материальных) показателей устойчивого организационного развития. Теория бизнес-укладов и системно-креативный подход к решению слабо формализованных задач [11] как научно-методическая основа для исследования и реализации концепции устойчивого развития экономических систем микроуровня, должны быть учтены в планировании развитием вуза.

В зоне ответственности НИУ находится повышение степени формализации и снижение степени абстрактности понимания концепции устойчивого развития реального сектора экономики. В зоне ответственности бизнеса лежит реализация данной концепции с применением научно обоснованных методик управления. В технической политике организации должны быть предусмотрены механизмы запроса и регулярной интеграции новых знаний в производственно-экономическую деятельность. В зоне ответственности государства лежит формирование условий и механизмов безбарьерного взаимодействия вуза с реальным сектором российской экономики.

\section{Библиографический список}

1. Портал Всемирной Организации Интеллектуальной Собственности [Электронный pecypc] URL: http://www. wipo.int/pressroom/ru/archive.jsp (дата обращения: 16.10.2018)

2. Китай выводит число международных патентных заявок на рекордно высокий уровень; растет спрос на охрану товарных знаков и промышленных образцов [Электронный ресурс] URL: http://www.wipo.int/ pressroom/ru/articles/2018/article_0002.html (дата обращения: 16.10.2018).

3. Кустов Е.Ф., Лозенко В.К., Оклей П.И., Муборакшоева Д. Т. Лучшая практика и патенты - стимул развития // Стандарты и качество № 7(949). 2016. Стр. 88-92.

4. Тульчинская Я.И., Курочкин Д. С. Методика оценки уровня технологического уклада страны // Наука и образование: хозяйство и экономика. 2013. № 5. С. 43-47.

5. Индикаторы инновационной деятельности: 2018: статистический сборник / Н. В. Городникова, Л.М. Гохберг, К.А. Дитковский и др.; Нац. исслед. ун-т «Высшая школа экономики».- М.: НИУ ВШЭ, 2018. - 344 с. 300 эк3. - ISBN978-5-7598-1742-0 (в обл.).

6. Лозенко В.К. Эволюция бизнесценозов и бизнесукладов в экономике / В.К. Лозенко. - Saarbrücken, LAP LAMBERT Academic Publishing. - 2013. - 181 c. - ISBN978-3-659-98721-2.4.

7. Лозенко В.К., Тульчинская Я.И. Научно-методический подход к оценке уровня технологического уклада электроэнергетической отрасли России // Вестник Южно-Российского государственного технического университета (Новочеркасского политехнического института). Серия: Социально-экономические науки. 2013.№ 1. C. 16-29.

8. Лозенко В.К., Михеев Д.В. Управление энергоэффективностью и устойчивое развитие организаций // Saarbrücken, LAP LAMBERT Academic Publishing, 2016. 284 c. ISBN978-3-659-66625-4.

9. Ицковиц Г. Тройная спираль: университеты-предприятия-государство: инновации в действии // Пер. с англ. / под ред. А.Ф. Уварова. Томск. 2010. 237 с. 
10. Абрамова Е.Ю., Курочкин Д.С., Лозенко В.К. Принципы взаимодействия с работодателями в рамках формирования набора компетентностей выпускника вуза // Экономика и управление: проблемы, решения. 2016. T. 2. № 9. С. 253-260

11. Лозенко В.К., Михеев Д.В., Сухарева Е.В., Шиндина Т.А. Теория бизнес-укладов и системно-креативный подход как методологическая основа для реализации концепции устойчивого развития промышленных предприятий // Микроэкономика. 2018. № 4. С. 7-14.

Поступила в редакцию 30.10.2018 